\title{
Effect of helmet wear on the incidence of head/face and cervical spine injuries in young skiers and snowboarders
}

\author{
A J Macnab, T Smith, F A Gagnon, M Macnab
}

Injury Prevention 2002;8:324-327

\begin{abstract}
Purpose: To evaluate whether helmets increase the incidence and/or severity of cervical spine injury; decrease the incidence of head injury; and/or increase the incidence of collisions (as a reflection of adverse effects on peripheral vision and/or auditory acuity) among young skiers and snowboarders. Methods: During one ski season (1998-99) at a world class ski resort, all young skiers and snowboarders (<13 years of age) presenting with head, face, or neck injury to the one central medical facility at the base of the mountain were identified. On presentation to the clinic, subjects or their parents completed a questionnaire reviewing their use of helmets and circumstances surrounding the injury event. Physicians documented the site and severity of injury, investigations, and disposition of each patient. Concurrently, counts were made at the entry to the ski area of the number of skiers and snowboarders wearing helmets. Results: Seventy children were evaluated at the clinic following ski/snowboard related head, neck, and face injuries. Fourteen did not require investigation or treatment. Of the remaining 56, 17 (30\%) were wearing helmets and $39(70 \%)$ were not. No serious neck injury occurred in either group. Using helmet-use data from the hill, among those under 13 years of age, failure to wear a helmet increased the risk of head, neck, or face injury (relative risk (RR) 2.24, 95\% confidence interval (CI) 1.23 to 4.12). When corrected for activity, RR was 1.77 and $95 \% \mathrm{Cl} 0.98$ to 3.19 . There was no significant difference in the odds ratio for collisions. The two groups may have been different in terms of various relevant characteristics not evaluated. No separate analysis of catastrophic injuries was possible.

Conclusion: This study suggests that, in skiers and snowboarders under 13 years of age, helmet use does not increase the incidence of cervical spine injury and does reduce the incidence of head injury requiring investigation and/or treatment.
\end{abstract}

See end of article for authors' affiliations

$\mathrm{H}$ ead, neck, and spinal cord injuries are the most costly sports injuries, both in terms of care costs and humanitarian costs. Reported incidences of head injury among skiers and snowboarders vary widely, depending on the location, age group, the specific sport, the source of the data (ski patrol, local clinic, emergency department, tertiary care neurology unit), and the quality of the denominator data, but overall, there are about 15 head injuries per million visits. ${ }^{1-3}$ In the 25 years before helmets became readily available, the incidence did not change significantly. ${ }^{1}$ According to Josefson, $2.6 \%$ of all skiing/snowboarding injuries are potentially serious head injuries. ${ }^{4}$ Levy and Smith report that head injuries constitute 3\% to $15 \%$, and spinal injuries constitute $1 \%$ to $13 \%$ of ski and snowboard injuries. ${ }^{5}$ In our previous study, children were found to have twice the incidence of injury to the head, face, and neck as other age groups, ${ }^{6}$ and $22 \%$ of head injuries were serious enough to cause loss of consciousness or clinical signs of concussion. ${ }^{\circ}$

Historically, in reports of injuries to skiers and snowboarders, there has been no mention of helmet use. One author commented that helmet use was uncommon. ${ }^{7}$ While helmet use for skiing and snowboarding is increasingly encouraged, and there has been increasing availability and use of helmets, ${ }^{8}$ recommendations are generally based on data from bicycle helmet studies. There is no study that clearly demonstrates the effectiveness of helmets in head injury prevention for skiers and snowboarders, and there is also a possibility that helmets contribute to cervical spine injury, increasing either the incidence or the severity of injuries. ${ }^{1}$ Furthermore, helmets may affect peripheral vision and auditory acuity, and thus contribute to increasing the incidence of collisions, ${ }^{510}$ the cause of the most severe injuries. ${ }^{511} 12$
We began the process of developing scientifically based ski injury prevention strategies by conducting a study of all injuries reported to the ski patrol during a complete ski season at a Canadian ski resort. ${ }^{6}$ This process has recently been recommended by Goulet et al and Kok and Bouter. ${ }^{13}{ }^{14}$ Subsequently, we researched behaviours underlying injury at the same location, and proposed physician directed injury prevention strategies for young skiers and snowboarders. ${ }^{15}$ However, two fundamental questions remained: (1) does the use of head protection reduce the incidence or severity of injury and (2) more particularly from the perspective of injury prevention advocacy for youth, is there an increased risk of cervical spine injury when head protection is worn by children? These questions are clearly not unique to Canada, are shared by many national organizations, and underlie the reluctance of organizations such as the American Medical Association to mandate helmet use or even to recommend that young skiers and snowboarders wear helmets. Both the American and Canadian Medical Associations recommend voluntary use of head protection, but these are not evidence based, recommendations.

This prospective study was conducted to investigate the possible contribution of helmets to head and cervical trauma, and the incidence of collision in young skiers and snowboarders.

Our null hypothesis was that helmet wear would not increase the incidence of neck injury among children under 13 years of age. We also hypothesized that helmet wear would not increase the incidence of head injuries in this group.

Abbreviations: $\mathrm{Cl}$, confidence interval; $\mathrm{RR}$, relative risk 


\section{METHODS}

This study was approved by the University of British Columbia Clinical Research Ethics Board (\#C97-0437). During one ski season (November 1998 to May 1999) at a major ski resort, we prospectively identified all young skiers and snowboarders ( $<13$ years of age) presenting with head, face, or neck injuries to the one central medical facility at the base of the mountain. A pilot study was conducted the previous year to establish the process for the clinic to administer and collect the questionnaires and optimize recruitment. At the time of presentation to the clinic, individuals or their parents were asked to complete a questionnaire reviewing their use of helmets and the circumstances surrounding the event causing the injury. Physicians recorded data on helmet wear, site and severity of injury, and investigation, treatment, and disposition. Injury was scored as inconsequential (no investigation, no treatment), minor (investigation, local treatment) or major (investigation and referral to hospital for further investigation/ treatment/follow up). Although medical staff entered data prospectively, a retrospective check of clinic records was made to ensure there were no cases missed. We were able to identify three additional cases through the chart review. We also cross checked the list of patients with the ski patrol records, which document ski patrol involvement with the injured on the mountain, how they are transported, and the destination of the patient after the incident.

Concurrently, counts of the number of skiers and snowboarders wearing helmets were made at the entry to the ski area. Two individuals simultaneously made unobtrusive observations on each person entering the lowest lift area. Observers recorded age group (by ticket being worn), equipment being carried ( skis $v$ snowboards), and helmet use. Tickets were classified as child (0-6), youth (6-12), and adult ( 13 and over). Counts were done for short periods ( $<2$ hours) to minimize the possibility of counting the same person twice. One day of observation was used for practice to improve accuracy and refine the counting methods. One observer used a hand held click counter to obtain a total count. Three other observers used pencil/paper to count specific groups: 1 for adults with helmets, 1 for adults without helmet, and 1 for children with or without helmets. By the second day, difference between the total counts and the sum of the three other observers was less than $1 \%$.

Observations were made on seven occasions, and included mornings and afternoons, weekdays and weekends, but excluded school holidays. The timing of the counts were selected to minimize bias without continuous long term observation (which was not within the budget). Data were extrapolated from these observations to the number of "skier visits" recorded by the ticket computer. The ticket computer recorded each visit, whether the person had a standard ticket, a special ticket, or a season's pass. There was no special mechanism devised to deal with siblings or groups. It was assumed that varying the month and day of week would provide a representative cross section.

Computer data generated by the ski patrol were compared retrospectively with our clinic data to determine whether any children with significant injuries were missed in our data collection because of transfer to a destination other than the clinic.

The sample size required ( $\mathrm{n}=33500$ skier visits per group) was estimated based on our previous data, with an expected incidence of helmet wear of $50 \%$ among the youth population, an incidence of head injury of 1.4 per 1000 skier visits, a strong experimental effect $(50 \%)$, a significance level of 0.05 , and a power of 0.8 . We anticipated that this sample size could be obtained in one season. Mantel-Haenszsel and $\chi^{2}$ tests were used to determine whether helmet use decreased the incidence of head injury.

\begin{tabular}{lll} 
Table 1 & Helmet wear by activity on the hill \\
\hline Group & No (\%) total & $\begin{array}{l}\text { No (\%) wearing } \\
\text { helmet }\end{array}$ \\
\hline $\begin{array}{lll}\text { Skiers } \\
\text { Snowboarders }\end{array}$ & $204(6.9)$ & $111(54.4)$ \\
& $47(5.5)$ & $13(27.7)$
\end{tabular}

\section{RESULTS}

The data obtained from the on-hill survey on the numbers of skiers and snowboarders wearing and not wearing helmets as they entered the ski area are presented in table 1. Among those under $13,54 \%$ of skiers were wearing helmets compared with $28 \%$ of snowboarders.

There were 70 children under 13 years of age evaluated at the clinic for ski/snowboard related head, neck, and face injuries. The ski patrol records identified 1517 individuals with injuries, 157 with head/face/neck injuries. The total number identified at the clinic, including all adults, for comparison with the ski patrol data (which uses different age criteria to define its groups, for example, 1-19 as the youngest group), was 676 , or 4.3 times as many. There were no patients identified by the ski patrol but missed by our data collection.

Of the 70 children assessed at the clinic, 14 were not deemed to require investigation or treatment of these, five were wearing helmets (36\%). Among the remaining 56, 17 $(30 \%)$ were wearing helmets, and $39(70 \%)$ were not. There was no significant difference in helmet use between those requiring, and those not requiring, investigation. Data on activity and helmet use for all minor and major injuries are presented in table 2 .

There were two children who suffered major injuries. Both, one a boy wearing a hockey helmet, and the other a girl not wearing a helmet, suffered closed head injuries while skiing.

Relative risk (RR) of head, face and/or neck injury for those under 13 was determined using on-hill helmet use statistics and the total number of ski visits for the year $(n=816837)$ for denominator data. Among those without helmets, RR of head/neck/face injury was 2.24 (95\% confidence interval (CI) 1.23 to 4.12 ) compared with those who wore helmets. Relative risk was also calculated for the specific activities: skiing RR 1.74 (95\% CI 0.82 to 3.73); snowboarding RR 1.82 (95\% CI 0.59 to 6.31 ). Mantel-Haenzsel test was performed to assess confounding by activity. Relative risk, controlling for activity, was 1.77 ( $\mathrm{p}=0.055 ; 95 \%$ CI 0.99 to 3.19$)$.

Twenty two children suffered cervical spine injuries. Seven $(32 \%)$ were wearing a helmet at the time of the incident (RR $2.0,95 \%$ CI 0.80 to $5.65 ; \mathrm{p}=0.15$ for cervical spine injury when not wearing a helmet). None of the cervical spine injuries were considered major. All were musculoskeletal injuries. Four were combined with closed head injuries.

Cause of injury was evaluated to determine whether helmets contributed to collisions. Among the group wearing helmets, $48 \%$ were injured as a result of falling, $10 \%$ as a result of a collision, compared with $29 \%$ and $20 \%$ respectively among 
the group not wearing helmets. The RR for falls was higher among the group not wearing helmets (RR 2.24; 95\% CI 1.14 to $5.13 ; \mathrm{p}<0.02$ ) whereas the RR for collisions was not significantly different for the group not wearing helmets, compared to the group wearing helmets (RR 1.63; 95\% CI 0.3 to 8.55 ; $\mathrm{p}=0.75$ ).

\section{DISCUSSION}

This is the first report in the literature that specifically seeks to clarify the role of helmet wear in the prevention or causation of skiing and snowboarding head and cervical spine injuries. We found a decreased risk of head injury associated with wearing of head protection among young skiers and snowboarders. There was no increase in the risk of cervical spine injuries. There was no significant increase in the incidence of either collisions or falls associated with wearing a helmet. Because of the extent of cross checking and verification, we believe our current data are stronger than that reported previously by us ${ }^{26}{ }^{15}$ or other authors. ${ }^{16-18}$ The number of injuries identified at the clinic was 4.3 times greater than the number managed by the ski patrol. This observation is important, as reports based on ski patrol data will likely represent only a portion of the injured population.

\section{Cervical spine injuries}

Spinal fractures and spinal cord injuries are rare among skiers and snowboarders under 13. In one study in British Columbia, ${ }^{19}$ all 10 such injuries occurring in one season were among teens and young adults (age range 16-29), and the 18 cervical spine injuries in the study reported by Kip and Hunter were all in those over age 20 (mean 40.8). ${ }^{12}$ Another study by Floyd also found no cervical spine injuries among children over a 10 year period at a major destination ski resort. ${ }^{20} \mathrm{~A}$ study by Sacco et al found spine injuries "only among very young snowboarders, and skiers out of control". ${ }^{21}$ However, there is no information about the level of spinal injury, nor are actual numbers provided.

Cervical spine injuries can happen in even very young children. ${ }^{22}$ Thus, among those under 13 , the greatest concern associated with advocating helmet use is the possibility of generating cervical spine injuries when they have not previously been a problem. It has been reported that heavy motorcycle helmets increase the chances of basal skull fractures (among those who die as a result of a motorcycle crash). ${ }^{19}$ It would be logical to consider that there is an increased risk with helmets in young children because of the relative weight of the helmet to total body weight and the neck strength. Our study showed no increased risk of cervical spine injury with helmet wear in this group.

\section{Head injury}

Investigators whose reports of skiing and snowboarding injuries are based on admission to emergency or hospital indicate that head injury is the most frequent reason for admission, and constitutes $20 \%{ }^{16}{ }^{17}$ to $54 \%^{23}{ }^{24}$ of admissions. Among skiers and snowboarders, head injury is the most common cause of death, and in one Canadian study, there was an $8 \%$ mortality rate among those admitted with head injuries. ${ }^{25}$

Therefore, even if the majority of head injuries that are prevented are relatively minor ones, if the incidence of head injury is reduced by helmet use, as shown in this study, helmet wear should be advocated. Further studies are required before considering legislation of helmet wear, as suggested by $\mathrm{Oh}$ and Schmid, in 1983. ${ }^{26}$ The US Consumer Product Safety Commission suggests that $53 \%$ of skiing and snowboarding head injuries among children could be prevented or reduced in severity if skiers and snowboarders wore helmets. ${ }^{3}$ Furthermore, it is likely that helmet use among those under 13 is cost effective, as Kopjar and Wickizer found for bicycle helmet use in this group. $^{27}$

\section{Key points}

- Helmet wear in skiers and snowboarders appears to decrease the risk of head injury among those under 13 years.

- Helmet wear likely does not increase the incidence and/or severity of neck injury in skiers and snowboarders under 13 years.

However, as the principle causes of head injuries differ between snowboarders and skiers-snowboarders often have occipital injuries from jumps, whereas the most severe injuries among skiers result from collisions with trees ${ }^{25}$ - their helmet needs likely differ, ${ }^{5}$ and it will take significant research to address this issue.

\section{Limitations}

Two limitations of this study merit particular emphasis:

- The small number of cases of head and spinal injury among skiers and snowboarders renders the power of the study relatively low, although it was sufficient to answer the questions asked. There was no attempt to address possible confounders.

- There is a possibility of confounding differences between the groups because, without information concerning the reasons for helmet use or non-use (such as personality or parental influence), it cannot be confidently stated that the two groups are similar. Further studies will be needed to examine ski habits and reasons for wearing helmets, to determine whether those who wear helmets are at higher risk, either through risk taking behaviours or lack of experience. Because of the number of possible confounders that need to be investigated, addressing this question will require a study of a different order of magnitude, with substantial funding and multicentre involvement.

There was no method for documenting observations on groups such as families or school groups that might have similar helmet use, and therefore the confidence limits may be somewhat narrow. However, groups are part of the skiing/ snowboarding community, and each group would represent a very small portion of the on-hill counts. Thus this limitation is likely relatively insignificant.

Although we documented "helmet use" and requested information on the model, often this detail was not provided, and is therefore not reported here. However, we are aware that at least in two instances, the helmet being worn was not specifically designed for skiing-one child who suffered a significant head injury was wearing a hockey helmet, and one was wearing a kayaking helmet.

As part of this study, we attempted to enroll a sample population for audiology and visual field testing with and without helmets, but no subjects were willing to undergo testing, possibly because of the time commitment and the need to attend in the city of Vancouver.

Future studies are needed to document the differences in risk taking behaviours and experience levels between those who wear helmets and those who do not, in addition to documenting the difference in incidence of head and cervical spine injury.

\section{CONCLUSION}

There are now grounds for recommending helmet wear in skiers and snowboarders under 13 years of age, as helmet wear appears to decrease the risk of head injury in this population. In addition, this study suggests that the additional weight of a helmet does not increase the incidence and/or severity of cervical spine injury among young skiers and snowboarders. The incidence of collision as the cause of injury was not increased 
among those wearing helmets, but the incidence of falls as the cause of injury was higher among the helmeted group.

\section{ACKNOWLEDGEMENTS}

This study was funded by the Rick Hansen Foundation Neurotrauma Initiative. We would also like to acknowledge the assistance of the physicians and staff at the Whistler Medical Clinic, Whistler/ Blackcomb Ski Area (Intrawest), and the Whistler/Blackcomb Ski Patrol.

\section{Authors' affiliations}

A J Macnab, T Smith, F A Gagnon, M Macnab, Departments of Pediatrics and Orthopaedics, University of British Columbia, Vancouver, $\mathrm{BC}$

\section{REFERENCES}

1 Hunter RE. Skiing injuries. Am J Sport Med 1999;27:381-9.

2 Macnab AJ, Cadman RE, Gagnon F. Demographics of alpine skiing and snowboarding injury: lessons for prevention programs. Inj Prev 1996;2:286-9.

3 US Consumer Product Safety Commission. CPSC staff recommends use of helmets for skiers, snowboarders to prevent head injuries (cpsc.gov/cpscpub/prerel/prhtml99/99046.html).

4 Josefson D. US call for mandatory skiing helmets. BM 1998:316:167-72.

5 Levy AS, Smith RH. Neurologic injuries in skiers and snowboarders. Semin Neurol 2000;20:233-45.

6 Cadman RE, Macnab AJ. Age and gender: two epidemiological factors in skiing and snowboarding injuries. Tenth International Symposium on Ski Trauma and Skiing Safety. American Society for Testing and Materials, Philadelphia, 1996: 58-65

7 Fukuda O, Takaba M, Saito T, et al. Head injuries in snowboarders compared with head injuries in skiers. A prospective analysis of 1076 patients from 1994 to 1999 in Niigata, Japan. Am J Sports Med 2001;29:437-40.

8 Hennessey T, Morgan SJ, Elliot $\mathrm{P}$, et al. Helmet availability at skiing and snowboarding rental shops. A survey of Colorado ski resort rental practices. Am J Prev Med 2002;22:1 10-12.
9 Konrad ChJ, Fieber TS, Schuepfer GK, et al. Are fractures of the base of the skull influenced by the mass of the protective helmet? A retrospective study in fatally injured motorcyclists. J Trauma 1996;41:854-8.

10 Godbut H. Helmets for the hill. Snow Country 1996:181-3 (Dec)

11 Friermood TG, Messner DG, Brugman JL, et al. Save the trees: a comparative review of skier-tree collisions. J Orthop Trauma 1994:8:116-8.

12 Kip $\mathbf{P}$, Hunter RE. Cervical spinal fractures in Alpine skiers. Orthopedics 1995; 18:737-41.

13 Goulet CR, Grimard G, Valois G, et al. Risk factors associated with alpine skiing injuries in children. Am J Sports Med 1999;27:644-50.

14 Kok G, Bouter LM. On the importance of planned health education: prevention of ski injury as an example. Am J Sports Med 1990;18:600-5

15 Macnab AJ, Cadman R, Greenlaw J. Physician-directed injury prevention for young skiers and snowboarders. Paediatr Child Health 1998;3:325-9.

16 Chow TK, Corbett SW, Farstad DJ. Spectrum of injuries from snowboarding. J Trauma 1996;41:321-5.

17 Hackam DJ, Kreller M, Pearl RH. Snow-related recreational injuries in children: assessment of morbidity and management strategies. J Pediatr Surg 2000;35: 1409-10

18 Hagel BE, Meeuwisse WH, Mohtadi NG, et al. Skiing and snowboarding injuries in the children and adolescents of Southern Alberta. Clin J Sport Med 1999;9:9-17

19 Koo DW, Fish WW. Spinal cord injury and snowboarding-the British Columbia experience. Spinal Cord Medicine 1999;22:246-51.

20 Floyd T. Alpine skiing, snowboarding, and spine trauma. Arch Orthop Trauma Surg 2001;121:433-6.

21 Sacco DE, Sartorelli DH, Vane DW. Evaluation of alpine skiing and snowboarding injury in a northeastern state. J Trauma 1998;44:654-9.

22 Patrick DA, Bensard DD, Moore EE, et al. Cervical spine trauma in the injured child: a tragic injury with potential for salvageable functional outcome. J Pediatr Surg 2000;35:1571-5.

23 Prall JA, Winston KR, Brennan R. Severe snowboarding injuries. Injury 1995;26:539-42.

24 Furrer $M$, Erhart $S$, Frutiger $A$, et al. Severe skiing injuries: a retrospective analysis of 361 patients including mechanism of trauma, severity of injury, and mortality. J Trauma 1995;39:737-41.

25 Myles ST, Mohtadi NG, Schnittker J. Injuries to the nervous system and spine in downhill skiing. Can J Surg 1992;35:643-8.

26 Oh S, Schmid UD. Head injuries in childhood caused by skiing and their optimal prevention. Z Kinderchir 1983;38:66-72

27 Kopjar B, Wickizer TM. Age gradient in the cost-effectiveness of bicycle helmets. Prev Med 2000;30:401-6.

\section{LACUNAE}

\section{Darwin Awards 2002}

$\mathrm{D}$ arwin Award nominees get scarier and scarier every year. (The Darwin Awards are given to the person who did the gene pool the biggest service by killing themselves in the most extraordinarily stupid way.) Last year's winner was the fellow who was killed by a Coke machine which toppled over on top of him as he was attempting to tip a free soda out of it. The 2002 nominations include a 27 year old French woman who lost control of her car on a highway near Marseilles and crashed into a tree, seriously injuring her passenger and killing herself. As a commonplace road accident, this would not have qualified for a Darwin nomination, were it not for the fact that the driver's attention had been distracted by her Tamagotchi key ring (pocket animal), which had started urgently beeping for food as she drove along. In an attempt to press the correct buttons to save the Tamagotchi's life, the woman lost her own. And a man in Alabama who died from rattlesnake bites. It seems that he and a friend were playing a game of catch, using the rattlesnake as a ball. The friend - no doubt a future Darwin Awards candidate-was hospitalised. More information on the Darwin web site, www.darwinawards.com (submitted by Barry Pless).

\section{No bullet tax this year}

A proposed constitutional amendment to levy a nickel tax on every bullet sold in California will not be considered this year, meaning the first-in-the-nation measure would not reach voters until at least 2004 The measure cleared one Senate committee, but was pulled from consideration recently before it was to be heard in a second committee. Senator Perata had proposed that the 5 cent tax on each bullet go to hospital emergency rooms (from Contra Costa Times (California), August 2002).

Peter Jacobsen who submitted this item comments: "A bullet tax makes sense to me-the top four causes of premature death are, in order: tobacco, motor vehicles, firearms, and alcohol. Would it not make more sense to tax these four instead of income?" 